Revista Signos

2010 / 43

Número Especial

Monográfico $\mathrm{N}^{\circ} 1$

$91-117$

\title{
Estructura ilocucionaria y cortesía: La construcción de conocimiento y opinión en las cartas de lectores de ciencia
}

\author{
Guiomar Ciapuscio \\ Universidad de Buenos Aires \\ CONICET \\ Argentina
}

Resumen: Este artículo tiene como objetivo general aportar a la investigación de los géneros de opinión en la comunicación de ciencia, y de manera más específica, se propone avanzar en el conocimiento de las estructuras y recursos accionales e interaccionales que emplean especialistas y lectores para elaborar y construir opinión en el campo científico. Sobre la base de un corpus de cartas de lectores de la revista argentina Ciencia Hoy, se identifican y describen patrones de estructuras ilocutivas que caracterizan a las cartas polémicas y, de manera ejemplar, se profundiza en el trabajo de cortesía que los interlocutores realizan para evitar los efectos no deseados de los actos amenazantes de la imagen. El análisis realizado permite arribar a resultados empíricos fundados sobre este género particular, que presenta de manera compactada el diálogo, la réplica y la polémica que caracterizan la actividad científica; estos resultados podrían emplearse como insumos para desarrollar lineamientos e insumos para mejorar la competencia en géneros especializados.

Palabras Clave: Discurso científico, géneros, cartas de lectores, estructura ilocutiva, cortesía.

Recibido: 20-XI-2009

Aceptado: 24-V-2010
Correspondencia: Guiomar Ciapuscio (gciapusc@retina.ar). Instituto de Filología y Literaturas Hispánicas Dr. Amado Alonso, Facultad de Filosofía y Letras, Universidad de Buenos Aires. Buenos Aires, Argentina. 


\title{
Estrutura ilocucionaria e cortesia: A construção de conhecimento e opinião nas cartas de leitores de ciência
}

Resumo: Este artigo tem como objetivo geral contribuir para pesquisa dos gêneros de opinião na comunicação de ciência, e de maneira mais específica, se propõe avançar no conhecimento das estruturas e recursos acionais e interacionais que empregam especialistas e leitores para elaborar e construir opinião no campo científico. Sobre a base de um corpus de cartas de leitores da revista argentina Ciencia Hoy, se identificam e descrevem padrões de estruturas ilocutivas que caracterizam as cartas polêmicas e, de maneira exemplar, se aprofunda no trabalho de cortesia que os interlocutores realizam para evitar os efeitos não desejados dos atos ameaçantes da imagem. A análise realizada permite chegar a resultados empíricos fundados sobre este gênero particular, que apresenta de maneira compactada o diálogo, a réplica e a polêmica que caracterizam a atividade científica; estes resultados poderiam ser empregados como insumos para desenvolver lineamentos e inputs para melhorar o desempenho em gêneros especializados.

Palavras-Chave: Discurso científico, gêneros, cartas de leitores, estrutura ilocutiva, cortesia.

\section{Illocutionary structure and politeness: Building knowledge and opinion in letters from readers of scientific topics}

\begin{abstract}
This paper seeks to contribute to the research on opinion genres in scientific communication. More specifically, it intends to broaden the knowledge of actional and interactional structures and resources that scholars and readers use to create and build scientific opinion. Based on letters sent to the Argentinean magazine Ciencia Hoy, illocutionary patterns typical of controversial letters are identified and described. Moreover, the politeness forms that readers use to deflect the undesirable effects of the threatening acts entailed in their images are addressed in depth. The analysis reveals empirical results based on this particular genre, which succinctly presents the triad dialogue/reply/controversy typical of scientific endeavor. These results could be applied as inputs for providing guidelines and as inputs for upgrading skills in specialized genres.
\end{abstract}

Key Words: Scientific discourse, genres, letters from readers, illocutionary structure, politeness.

\section{INTRODUCCIÓN}

Este trabajo tiene como objetivo general aportar al conocimiento de los géneros de opinión en la comunicación de ciencia y, como objetivo específico, profundizar en el conocimiento de la estructura ilocucionaria y el trabajo de cortesía que presentan las cartas de lectores de una revista de ciencia; de esta manera se espera avanzar en la comprensión de los modos en que los lectores, editores y especialistas presentan, discuten y elaboran los sucesos y temas científicos y, de este modo, construyen opinión y juicio crítico sobre los mismos en el ámbito de la comunidad de discurso que forman los lectores de la revista Ciencia Hoy, una revista de divulgación científica de la Argentina. 
Según mi conocimiento, los géneros de opinión en ciencia, a diferencia de los destinados a la investigación y comunicación de resultados, han sido escasamente tratados por la literatura; sin embargo, por sus propiedades funcionales y retórico-lingüísticas, ofrecen un campo fértil para comprender el modo en que se construye, se discute y se reformula el conocimiento científico y las posiciones sobre los hechos y estados de cosas referidos en los textos.

\section{Fundamentos teóricos}

\subsection{Los conceptos de 'texto', 'género' y 'familias genéricas'}

El presente trabajo se enmarca en el enfoque denominado 'cognitivo-comunicativo' de la lingüística textual alemana (Heinemann \& Viehweger, 1991; Heinemann, 2000; Heinemann \& Heinemann, 2002). Los textos son comprendidos como 'actividades comunicativas' destinadas al logro de objetivos; se toma como punto de partida la totalidad textual (la perspectiva es top-down) y su inclusión en marcos de actividades superiores; por otra parte, se asume que los textos son empleados en contextos específicos y que desempeñan funciones comunicativas y sociales. Un individuo que produce o comprende un texto pone en juego, a partir de un conjunto de esquemas de operaciones cognitivas, variados sistemas de conocimientos interrelacionados. Los textos, entonces, son concebidos como entidades primariamente psíquicas; considerados desde la perspectiva del resultado, los textos son productos de procesos mentales: son objetos complejos y naturales (Bernárdez, 1995), y se caracterizan por la propiedad de la textualidad, que consiste en un conjunto de atributos, que atañen a las distintas dimensiones constitutivas de los textos: la funcionalidad, que está en el centro de los criterios de textualidad (Heinemann \& Heinemann, 2002), la situacionalidad, la tematicidad, la coherencia y la cohesión. Por otra parte, todo texto es siempre un representante de un género de textos; el concepto de género puede describirse inicialmente en términos de agrupaciones de textos a partir de cualidades referidas a sus dimensiones constitutivas y distintivas que los hablantes de una lengua pueden realizar sobre la base de sus experiencias comunicativas (Heinemann, 2000).

Heinemann y Heinemann (2002) proponen como instrumento descriptivo de los géneros una tipología multidimensional -que es un modo de representar los conocimientos genéricos y su instanciación en producciones verbales complejas- que comprende los niveles de la 'funcionalidad', la 'situacionalidad', 'tematicidad' y 'estructura', y 'adecuación de la formulación', niveles que, como ya se dijo, definen al texto. En la Tabla 1 se presenta un esquema de las dimensiones con sus principales categorías distintivas. 
Tabla 1. Dimensiones textuales (a partir de Heinemann \& Heinemann, 2002).

\begin{tabular}{|l|l|}
\hline $\begin{array}{l}\text { Nivel 1: } \\
\text { Funcionalidad }\end{array}$ & $\begin{array}{l}\text { (Macro) Funciones principales: a) Expresarse; b) Contactar; c) Informar; d) Dirigir; e) } \\
\text { Producir efectos estéticos. }\end{array}$ \\
\hline $\begin{array}{l}\text { Nivel 2: } \\
\text { Situacionalidad }\end{array}$ & $\begin{array}{l}\text { Parámetros: a) Situación de actividad; b) Organización social de las actividades en } \\
\text { ámbitos comunicativos; c) Medio/canal; d) Número de interlocutores; e) Papeles } \\
\text { sociales de los interactuantes; f) Situación contextual. }\end{array}$ \\
\hline $\begin{array}{l}\text { Nivel 3: } \\
\begin{array}{l}\text { Contenido } \\
\text { semántico y } \\
\text { estructura }\end{array}\end{array}$ & $\begin{array}{l}\text { Parámetros: a) Impronta temática (grado de fijación del tema textual); b) Modos de } \\
\text { despliegue del tema textual; c) Estructura del texto. }\end{array}$ \\
\hline $\begin{array}{l}\text { Nivel 4: } \\
\text { Forma lingüística }\end{array}$ & $\begin{array}{l}\text { Parámetros: a) Máximas comunicativas; b) Esquemas de formulación específicos del } \\
\text { género; c) Particularidades estilísticas, rasgos léxico-gramaticales. }\end{array}$ \\
\hline
\end{tabular}

Este instrumento descriptivo y tipológico permite analizar y contrastar diferentes géneros, a partir de las distinciones categoriales de los niveles textuales y sus 'valores' particulares en la forma de rasgos específicos. Más allá de su potencialidad descriptiva, los modelos jerárquicos como el de la Figura 1, representados generalmente de manera vertical (Brinker, 2001, 1988; Heinemann \& Viehweger, 1991; Heinemann, 2000; Heinemann \& Heinemann, 2002, entre otros), no resultan siempre adecuados desde el punto de vista empírico, puesto que las informaciones de las distintas dimensiones se condicionan recíprocamente y no solo en una dirección y, frecuentemente, son difíciles de deslindar con claridad, según los niveles ${ }^{1}$.

Los géneros consisten en representaciones prototípicas en los distintos niveles de configuración textual: así, una carta, o mejor, el conocimiento social sobre el género 'carta', incluye una serie de representaciones de naturaleza prototípica sobre algunas dimensiones textuales: por ejemplo, los hablantes evocan como rasgos distintivos factores de orden situacional como 'interacción entre dos o más hablantes', 'distancia temporal y espacial', 'comunicación escrita', etc.; también factores de orden estructural relativos a las partes típicas como:

- fecha y encabezamiento

- introducción

- cuerpo de la carta

- despedida y firma

- $\quad$ posdata, notas (parte accesoria) $)^{2}$

Además, esos conocimientos de orden situacional y estructural están ligados a informaciones de orden lingüístico-gramatical: fórmulas de tratamiento para dirigirse al interlocutor, rutinas formales para los saludos, construcciones estereotipadas para determinados pasos procedimen- 
tales del género, etc. Sin embargo, estas representaciones son de orden ideal y tienen un alto grado de generalidad. Naturalmente, los distintos subgéneros del discurso epistolar pueden distinguirse a partir de especificaciones adicionales en las distintas dimensiones textuales.

Es claro que un mismo texto puede asignarse eventualmente a dos o a varias clases de textos (géneros) mayores. En el siguiente esquema, la clase 'carta de lectores' es representante de la clase mayor 'cartas' (que incluye otras subclases, como cartas de amor, cartas comerciales, etc.) pero también puede verse como un texto del ámbito periodístico, en dependencia del punto de vista. Además, podría suponerse otra agrupación en una clase textual mayor, motivada en razones temáticas: por ejemplo ‘textos que tratan temas amorosos’ (Heinemann \& Heinemann, 2002):

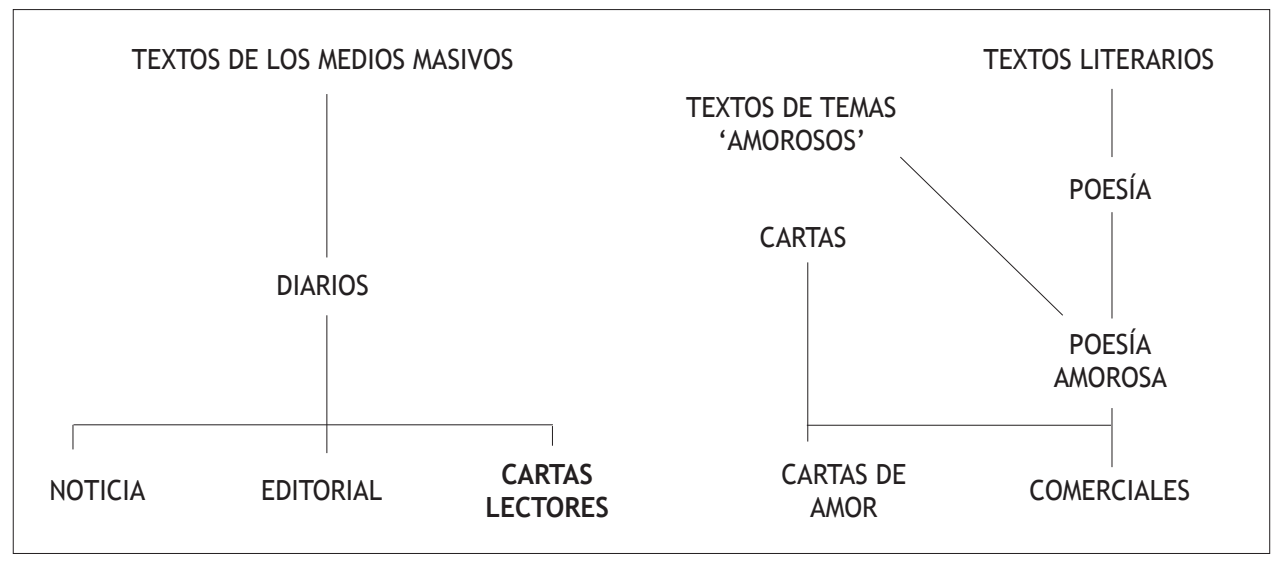

Figura 1. El género ‘cartas'.

En efecto, los distintos géneros que emplea una comunidad no están desvinculados entre sí, sino que hay relaciones entre ellos, incluso zonas de solapamiento. ¿Cómo capturar las relaciones entre géneros? Los modos de interpretar los vínculos entre los géneros varían como también las terminologías varían en los distintos enfoques; pensadores de orientación sociológicocomunicativa han propuesto el término de 'familias' (Bergmann \& Luckmann, 1995), término que permite capturar mejor la naturaleza dinámica de los géneros y representar la idea de Bergmann y Luckmann (1995) de que cada ámbito de actividad desarrolla sus propias formas genéricas como estrategias de solución preformadas para las tareas propias (y regulares) de 
ese ámbito (Ciapuscio, 2007). La metáfora de 'familia' sugiere que las relaciones entre géneros van más allá del mero compartir un territorio en términos de mayor proximidad o lejanía, hace más nítida la existencia de vínculos entre los géneros y, fundamentalmente, permite expresar la idea de que los miembros de la familia desempeñan distintos roles en el marco general accional que les da origen y sentido. Las cartas de lectores de revistas de ciencia cumplen un papel específico en el ámbito discursivo propio y conllevan una serie de propiedades derivadas de los condicionamientos del ámbito en las distintas dimensiones textuales.

\subsection{Estructura ilocutiva y trabajo de cortesía}

En este estudio profundizaré en la dimensión funcional del género (Tabla 1, nivel 1) a partir de su materialización lingüística (Tabla 1, nivel 4); por ello los actos de habla y los recursos lingüísticos para su formulación serán el foco del análisis.

Como fundamento teórico tomo el trabajo de Brandt y Rosengren (1992) quienes parten del supuesto de que el texto -considerado como producto verbal- debe entenderse como resultado de la interacción de dos módulos principales: el módulo pragmático y el módulo gramatical. Si se considera el módulo pragmático, se identifican las unidades de acción, es decir, las ilocuciones, las cuales siempre portan unidades informativas: la relación entre ilocución y unidad informativa es de condicionamiento mutuo pero no necesariamente una relación uno a uno. Varias ilocuciones conforman la estructura ilocutiva, la cual se conforma a partir determinados principios del módulo pragmático: la estructura ilocutiva es compleja, por lo que deben distinguirse al menos dos niveles: el nivel de la jerarquía ilocutiva y el nivel secuencial (del mismo modo que la unidad oración en el nivel gramatical exhibe una organización jerárquica y lineal). Las autoras parten de la base de que existe un principio general superior que sigue todo productor de un texto y que determina la construcción de la jerarquía ilocutiva: ese principio es el 'principio del éxito': el productor sabe que frecuentemente no es suficiente realizar una determinada acción lingüística para alcanzar el resultado deseado, sino que para tener éxito debe realizar esfuerzos adicionales con ilocuciones subsidiarias o de apoyo, que sustenten las ilocuciones dominantes o principales, que responden al objetivo fundamental del productor textual. Se distinguen dos subtipos de ilocuciones de apoyo: por un lado, aquellas que tienen por objetivo directo asegurar el éxito de la ilocución dominante (son ilocuciones que se relacionan con las condiciones de éxito y se orientan a que el interlocutor comprenda y acepte lo que el productor quiere de él y de la interacción); por el otro lado, existen ilocuciones de apoyo que colaboran de manera solo indirecta con la ilocución principal: se trata de las ilocuciones complementarias. Estas apuntan o bien al contexto comunicativo (especialmente, referencias intertextuales a interacciones previas relacionadas con el tema) o bien tratan de asegurar la cooperación mediante actos amables ('agradecimientos', 'felicitaciones', ' halagos'). 
En cuanto a la estructura lineal de las ilocuciones en el texto está determinada por principios de distinto orden: el tipo de contenidos, el género del texto, la relación entre los interlocutores, el contexto, etc. En un corpus amplio de cartas comerciales las autoras fundamentan dos tipos de jerarquías ilocutivas: la jerarquía simple (al menos una ilocución fundamental y una ilocución de apoyo) y la jerarquía compleja (compuesta de varias jerarquías). Las jerarquías identificadas se disponen en esquemas arbóreos que, entre otros aspectos, muestran cómo la estructura secuencial de las ilocuciones no se corresponde con la estructura jerárquica.

Los actos de habla o ilocuciones principales de las cartas que serán el foco de mi análisis representan lo que Brandt y Rosengren (1992) describen en su corpus como 'directivos complejos': mientras que en las cartas comerciales se trata de jerarquías compuestas de 'pedidos', 'órdenes', 'exigencias', etc., en las cartas de lectores sobre temas de ciencia, las ilocuciones directivas dominantes constituyen 'réplicas', 'críticas', 'admisiones', 'refutaciones', etc. Como es sabido, los actos directivos en general implican un riesgo cierto de afectar negativamente la relación interpersonal -la imagen (Gooffman, 1967)- y la preservación del principio de cortesía. Las cartas de lectores del corpus incluyen de manera distintiva actos de habla amenazantes para la imagen del destinatario (Face-threatening acts, Brown \& Levinson, 1987) que realizan lo que Leech (1983) ha caracterizado como cortesía absoluta, puesto que son inherentemente descorteses. Concretamente, el desafío que afrontan los escritores de estos textos es extremar el trabajo de cortesía negativa ("minimizar la descortesía de las ilocuciones descorteses", Leech, 1983: 81), y esforzarse por incluir ilocuciones corteses y maximizar su cortesía positi$\mathrm{va}^{3}$. Así se vuelven muy relevantes no solo las estrategias y recursos para realizar esos actos de habla (esto es, los medios lingüísticos para expresar la modalidad, el grado de compromiso del hablante, etc.), sino también los medios para mitigar las expresiones, es decir, el tratamiento de la imagen. Siguiendo a Caffi (1999) empleo el término 'mitigación' en un sentido amplio, incluyendo todos los recursos para 'bajar el tono', (inglés, downgrading, alemán, Abschwächung) y en el sentido más estrecho, ligado a los actos amenazantes de la imagen. La mitigación puede tener diferentes alcances: el contenido proposicional (en donde funcionan como mitigadores los hedges proposicionales o bushes), las ilocuciones (el compromiso del hablante respecto del contenido proposicional, campo en el que funcionan los hedges) y el origen deíctico de la expresión (las instancias de enunciación, en que son relevantes los escudos, o recursos para despersonalizar o desagentivar las expresiones) ${ }^{4}$. 


\section{Materiales y métodos}

Las cartas de lectores se extrajeron de 18 números de la revista correspondientes a los años 2005, 2006 y 2007 de la revista Ciencia Hoy ${ }^{5}$, los que forman parte del corpus COTECA (Corpus Textual del Español Científico de la Argentina ${ }^{6}$ ); la muestra se compone entonces de 48 textos, informatizados y tipologizados de acuerdo con la metodología del proyecto. Ciencia Hoy fue fundada en los tiempos de la restauración democrática argentina como contraparte en español de la brasileña Ciencia Hoje. Con una frecuencia bimestral, está dirigida a un público amplio7; en ella se publican resultados de investigaciones llevadas a cabo por científicos argentinos y uruguayos, y de otros países latinoamericanos; difunde investigaciones que se realizan en el campo de las ciencias formales, naturales, sociales y de sus aplicaciones tecnológicas. Su primer número data de diciembre de 1988 y desde entonces ha logrado constituirse en la revista de divulgación científica de referencia de la Argentina. En su editorial fundacional se sostiene que:

"Ciencia Hoy aspira a ser más que un órgano de difusión de la ciencia. Quiere convertirse, además, en un espacio para la reflexión, la opinión y el debate: incluye secciones permanentes de noticias, entrevistas y comentarios, y sus páginas están abiertas a la comunidad científica para permitir que se exprese e interactúe con el resto de la sociedad" (Volumen 1, № 1, Diciembre/ Enero, 1989).

La revisión de los índices de la revista revela que esas tareas comunicativas son realizadas por medio de géneros estables ('Editorial', 'Cartas de lectores', ' Artículos'), y por otros géneros, como la 'entrevista' y secciones como 'Ciencia y Sociedad', 'Ciencia en el Mundo', 'Memoria de la ciencia', etc. que incluyen también artículos, aunque orientados a los contenidos de esas secciones, cuya ocurrencia no es obligatoria. Dentro de los géneros centrales corresponde hacer una distinción entre los géneros de opinión -distinguidos tipográficamente como un grupo en el índice- y los géneros más informativos ('el género central', 'el artículo', 'la entrevista', 'la guía didáctica’, etc.). Los géneros de opinión son los ‘editoriales’ (la voz institucional de la revista) y las 'cartas de lectores'.

En cuanto a los métodos empleados, si bien se han realizado algunas consideraciones cuantitativas que permiten visualizar estructuras y rasgos caracterizadores del género y del subgrupo de cartas que son el foco de este trabajo, el estudio tiene una impronta esencialmente cualitativa y se ha guiado por el instrumentarium teórico-metodológico expuesto en la sección 1. En este artículo, por razones de espacio, se ilustrarán en profundidad dos intercambios (cuatro cartas) que, según la investigación realizada, representan 'tipos' recurrentes o patrones de estructuración ilocutiva, y las estrategias y recursos del trabajo de cortesía que coadyuvan a su realización y al establecimiento de la relación entre los interlocutores. 


\section{Análisis}

\subsection{El género 'carta de lectores'}

Las cartas de lectores de Ciencia Hoy se asemejan a las cartas de lectores de los periódicos y revistas de la prensa general, en las que los lectores se dirigen al 'director' o a los 'editores' para emitir opinión, aportar información adicional o realizar reclamos o denuncias sobre un tema de interés general. Es frecuente que las cartas de lectores de la prensa escrita exhiban referencias intertextuales explícitas, que retoman temas o problemas de interés público. Las cartas de lectores de Ciencia Hoy tienen como rasgo característico el carácter intrínsecamente intertextual: se refieren de manera explícita a artículos u editoriales contenidos en otros números de la revista; el punto de referencia es siempre otro u otros textos, aparecidos en números anteriores. Además, en ocasiones, las cartas mismas se convierten en fuente de cartas posteriores, cuando su contenido desencadena respuestas o réplicas de otros autores. Es decir, la polémica que suele instaurarse mediante una carta de lector puede extenderse por varios números y convocar a las distintas voces responsables de los contenidos de la revista (no solo editores sino también los autores de los artículos) y a distintos perfiles de lectores.

¿Cuál es entonces la 'tarea’ o el papel socio-comunicativo que desempeña este género en la revista? Las 'cartas de lectores' de Ciencia Hoy son el género mediante el cual se entabla y se realiza el diálogo entre los editores, los lectores y los autores de los artículos, diálogo que, en no pocas ocasiones, se realiza bajo la forma de controversias que pueden alcanzar un alto grado de polémica. Es decir, el género es el espacio en que Ciencia Hoy promueve "la opinión y el debate" (cfr. supra). En términos generales, puede decirse que las cartas de lectores (en adelante, $\mathrm{CL}$ ) desempeñan tres 'funciones' principales:

a) DISCULPA por parte de los editores, por erratas de distinta gravedad;

b) LAUDATIO, encomio de los contenidos de los artículos publicados;

c) RÉPLICA o REFUTACIÓN, iniciada por los lectores, debido al desacuerdo con aspectos particulares o generales de los contenidos de los artículos o editoriales.

Un pequeño grupo de CL está compuesto por cartas escritas por pares, que tienen por propósito completar o aclarar información, o en menor medida, emitir opiniones sobre los temas en cuestión.

Desde el punto de vista 'temático', las cartas de lectores están acotadas a los temas particulares de los textos que les dan origen y que, obviamente, pertenecen al campo científico. Una observación general sobre los temas de las cartas del corpus muestra que suelen cobrar rele- 
vancia tanto aspectos conceptuales (contenidos específicos de los textos, datos de personas, números, lugares) como también -y bastante frecuentemente- temas relativos a las terminologías o nomenclaturas y cuestiones de normativa general.

Desde el punto de vista 'situacional', como todo género epistolar, se trata de un diálogo mediado por la escritura y signado por la distancia entre los interlocutores. Las cartas pueden ordenarse de acuerdo con la identidad de los productores y la existencia o no de respuestas posteriores. Los productores de las cartas de lectores responden a dos perfiles en la muestra analizada: por un lado, pares especialistas, expertos o autoridades de gestión político-científica que cuestionan o discrepan con aspectos particulares de los artículos o editoriales o, también, que participan aportando información u opiniones personales. Por otro lado, en menor medida, escriben cartas de lectores profesores de educación media -según los editores, uno de los destinatarios principales de la revista-, quienes en todos los casos se limitan a agradecer o alabar un artículo y a solicitar bibliografía adicional. Es decir, son los que escriben cartas exclusivamente laudatorias y no polémicas. Los lectores especialistas, por otra parte, escriben cartas del tipo c) RÉPLICA o las que tienen por objetivo aportar información adicional o emitir opinión.

En la Tabla 2 presento un ordenamiento de las cartas del corpus en tres categorías ( de acuerdo con los tipos de interlocutores, con la existencia o no de una respuesta posterior y según si la carta desata controversias que se prolongan en una o varias réplicas.

Tabla 2. Las cartas de lectores de Ciencia Hoy (sistematización).

\begin{tabular}{|c|c|c|c|c|}
\hline & $\begin{array}{l}\text { A) Carta de } \\
\text { editores - } \\
\text { respuesta }\end{array}$ & $\begin{array}{l}\text { B) Carta lectores +/- } \\
\text { respuesta }\end{array}$ & $\begin{array}{l}\text { C) Carta de } \\
\text { lectores + } \\
\text { Respuestas } \\
\text { (autores y/o } \\
\text { editores) }\end{array}$ & Totales \\
\hline $\begin{array}{l}\text { Controversia } \\
\text { e ilocuciones } \\
\text { principales }\end{array}$ & $\begin{array}{l}\text { - Controversia } \\
\text { (DISCULPARSE, } \\
\text { AGREGAR } \\
\text { INFORMACIÓN) }\end{array}$ & $\begin{array}{l}\text { - Controversia } \\
\text { (AGRADECER / } \\
\text { SOLICITAR/APORTAR } \\
\text { INFORMACIÓN, } \\
\text { CORREGIR) }\end{array}$ & $\begin{array}{l}\text { + Controversia } \\
\text { (REFUTAR, } \\
\text { CRITICAR, } \\
\text { ADMITIR) }\end{array}$ & $\begin{array}{l}\text { - C } 37,3 \% \\
+ \text { C } 62,7 \%\end{array}$ \\
\hline $\begin{array}{l}\text { Número de } \\
\text { textos por tipo } \\
\text { de cartas }\end{array}$ & $\begin{array}{l}4(8,30 \%) \\
C L 3,5,25 ; 17\end{array}$ & $\begin{array}{l}14(29 \%) \\
C L 2 \text { a y b; } 8,9,10 a \\
\text { y b, 11, 12, 14, 15, } \\
18,21,23,24\end{array}$ & $\begin{array}{l}30 \text { (62,7\%) } \\
\text { CL 1a y b; } 4 a \text { y b; } 7 \\
\text { a - h; } 13 a-d ; 16 \text { a y } \\
\text { b, } 19 \text { a y b, } 20 \text { a y } \\
\text { b, } 22 \text { a-d, } 26 \text { a y b, } \\
27 \text { a y b }\end{array}$ & 48 (100\%) \\
\hline
\end{tabular}


Los dos primeros grupos, A y B, se caracterizan por la ausencia de controversia y conforman el $37,3 \%$ del corpus. El grupo A, el más reducido, con solo cuatro ejemplares, corresponde a las cartas que escriben los editores para informar sobre erratas involuntarias en los artículos o editoriales de números anteriores, o que agregan información solicitada por los lectores (solo un caso). La información sobre erratas se presenta bajo la forma de ilocuciones informativas simples o estas se incluyen en una ilocución principal de orden expresivo, como lo muestra el siguiente caso:

Lamentamos tener que señalar dos erratas que empañaron el artículo sobre los premios Nobel aparecido en el número 84. En la nota de Fidel Schaposnik sobre el premio de física, si bien fue correcto que apareciera la letra griega alfa (a) en la primera oportunidad en que se la puso, en todas las otras constituye un error de imprenta. En esos casos tendría que haber salido la letra griega beta (B) (...) La otra errata es que (...).

En el grupo B se incluyen cartas formuladas por lectores especialistas o por docentes o aficionados a temas de ciencia, cuyo propósito es mayormente laudatorio. En el caso de las escritas por pares especialistas, generalmente reconocidos en la comunidad, las ilocuciones dominantes son de orden informativo, en ocasiones con propósitos de realizar correcciones y más asiduamente de agregar información o presentar opiniones sobre los temas de los artículos o números comentados. En el ejemplo que sigue, el autor de la carta, además, se presenta de manera explícita como participante del evento del artículo y, por tanto, opinante acreditado. Desde el punto de vista de la estructuración ilocutiva, como gran parte del corpus, suelen iniciarse con una ilocución expresiva laudatoria (AGRADECER, FELICITAR, etc.), acompañada de distintos recursos de cortesía, para luego introducir las informaciones o correcciones deseadas:

Como integrante del primer grupo de docentes del Instituto de Física de Bariloche, en 1955, felicito a los editores de Ciencia Hoy por la excelente cobertura del cincuentenario de la institución en el número 88 , y aprovecho para hacer algunos comentarios sobre INVAP SE....(CL0008).

Cuando los escritores son docentes o aficionados, los propósitos suelen ser mayormente laudatorios y, en ocasiones, también expresan su deseo de recibir más información; en todos los casos, inician su texto describiendo su perfil, como lo muestran los siguientes ejemplos:

Como profesor de biología de escuela media, me sentí movido a agradecer la publicación del artículo sobre la retama de Darwin (CL0002a).

Soy docente chaqueña de geografía y ciencias biológicas en los ciclos EGB3 y polimodal. Me resultaron cautivantes los artículos publicados en el número 87 (CL 0010a). 
Desde el punto de vista funcional, por tanto, dominan las ilocuciones de tipo EXPRESIvo como AGRADECER, FELIIITAR, SALUdAR POSITIVAMENTE, seguidas o no de DIRECTIVAS COMO SOLICITAR, PREGUNTAR, etc.

El grupo más interesante para este estudio es el $C$, que reúne la mayoría de las cartas del corpus $(62,5 \%$, es decir, 30 textos) y que se caracteriza por la presencia de controversia; estas cartas presentan situaciones dialógicas (cartas iniciadoras - cartas de respuesta), que incluyen la crítica, la réplica y la argumentación con un variado grado de polémica y trabajo de cortesía. Las 30 cartas representan en rigor 10 intercambios polémicos; en el corpus se identificaron mayormente pares de cartas (7), intercambios realizados mediante 4 cartas (2) y un intercambio muy extenso que abarcó varios números de la revista (8 cartas). De las controversias participan lectores, autores y editores. En ocasiones, cuando la polémica alcanza una relevancia especial, los editores actúan como 'coordinadores' de las mismas, es decir, las introducen e incluso las dan por concluidas explícitamente, como lo muestra el siguiente ejemplo:

Con la publicación de esta carta, Ciencia Hoy da por terminada la controversia suscitada por el artículo 'Impacto de los países escandinavos en el desarrollo de la física en la Argentina: 1960-2000', publicado en el número 88 de agosto/septiembre 2005, y ventilada en la sección Cartas de lectores de los números 89 y 91 . El lector podrá juzgar por sí mismo el valor de los argumentos (CL0007g).

\subsection{Estructura ilocutiva y trabajo de cortesía en las 'cartas controversiales'}

El análisis cualitativo del conjunto de 'cartas controversiales' permitió identificar ciertas regularidades en la estructuración ilocutiva y el trabajo de cortesía, que queremos tratar en detalle en esta sección. El punto de partida de estas interacciones es el desacuerdo total o parcial de los lectores respecto de aspectos específicos de los artículos o textos de la revista: ese desacuerdo se textualiza en todos los intercambios mediante actos de habla directos o indirectos fundamentales DIRECTIVOS ${ }^{8}$ del tipo CRITICAR que desencadenan un problema o conflicto, el cual se elabora y dirime en estos textos con distinto resultado, tanto en lo que se refiere a su resolución (acuerdo/desacuerdo) como a las imágenes de los interlocutores y su relación. Por otro lado, las respuestas a las cartas iniciadoras del conflicto contienen actos de habla fundamentales DIRECTIVOS del tipo REFUTAR y REPLICAR, y, en ocasiones, se pueden identificar también ilocuciones de ADmIsIón. El análisis realizado reveló que existen patrones recurrentes en la estructura ilocutiva de estas cartas controversiales, que pueden describirse y sistematizarse mediante el análisis lingüístico.

A los efectos de esta presentación, tomaré dos casos de este grupo, de carácter relativamente simple, puesto que se componen de la carta iniciadora del conflicto y su correspondiente respuesta por parte de los editores; los casos ilustran, por un lado, jerarquías ilocutivas simples 
y complejas, por el otro, trabajos de cortesía más o menos intensos por parte de los interlocutores. El análisis detallado permite identificar y describir las estrategias y los recursos que emplean los interlocutores -lectores y editores- para elaborar y dirimir las controversias, y de este modo constituir y reelaborar conocimiento y opiniones en la respectiva comunidad de discurso.

\subsubsection{Caso 1. Desacuerdo y descortesía}

El intercambio que presento como Caso 1 ilustra el patrón que puede describirse como 'desacuerdo y descortesía'. Para comenzar, cabe realizar una aclaración metodológica: como es sabido, a toda oración subyace una ilocución; sin embargo, también estructuras incrustadas, como las proposiciones subordinadas y cláusulas reducidas pueden tener su propia fuerza ilocucionaria. A los efectos de la simplicidad, aquí solo se tratan ilocuciones que portan estructuras menores a la oración cuando es imprescindible para la interpretación pragmática del texto. A continuación la carta iniciadora del primer conflicto9:

\section{Jubileo del Instituto Balseiro (CL0006a)}

1.1. La publicación del número 88 de la revista, dedicado en su totalidad al aniversario del Instituto Balseiro, me parece un acto de estricta justicia, dada la necesidad de revalorizar en la Argentina el esfuerzo, el estudio y la investigación científica. 1. Sin embargo, me resulta difícil encontrar otro motivo de elogio. 1.2. La totalidad de los artículos tiene un carácter histórico, de conmemoración de sucesos pasados. 1.3. Este particular enfoque hace que la lectura se haga pesada, porque los mismos nombres, hechos y circunstancias se repiten una y otra vez a lo largo de 60 páginas. 1.4. Comparto con el editor que "Comprender la historicidad y los componentes socioculturales de la producción científica y tecnológica resulta necesario", pero esta necesidad podría haberse reflejado en dos o tres crónicas o entrevistas (en cualquier caso, la investigación histórica del Balseiro no se agotó con este número de CIENCIA HOY). 1.5. La acumulación de notas históricas parece más propia de un obituario que del 50 aniversario de una institución en crecimiento. 1.6. Lamenté, fundamentalmente, la ausencia de notas de divulgación realizadas por investigadores actuales del instituto sobre las investigaciones en curso o proyectadas.

\section{Gerardo Rodríguez Planes}

Médico cirujano en los hospitales Churruca y Durand

Las cartas de lectores de Ciencia Hoy, como lo muestra el primer ejemplo, no presentan encabezamiento como es típico del género epistolar ${ }^{10}$; no hay mención del destinatario ni coordenadas temporales, sino que los editores colocan un título (temático) que orienta la lectura. Inmediatamente sigue el cuerpo de la carta, cuya extensión es muy variable ${ }^{11}$, que se cierra 
con el nombre del emisor, en ocasiones acompañado de datos sobre su profesión o papel institucional y la mención del lugar de residencia.

El autor de esta carta, a diferencia de la mayoría, toma como objeto de referencia la totalidad de un número de la revista dedicado al aniversario de una conocida institución científica argentina, y adopta una posición sumamente crítica, posición que verbaliza de manera directa, sin realizar trabajo de cortesía negativa alguno. Si se analizan las ilocuciones desde el punto de vista secuencial, se identifica una progresión muy habitual en las cartas del corpus: se inicia con una ilocución expresiva de apoyo (1.1.), del tipo complementario, que está orientada al trabajo interaccional (ALABAR: La publicación (...) me parece un acto de estricta justicia) y que desempeña la función que Gallardo (2005) ha llamado concesiva: el autor acuerda para luego disentir con el destinatario. A continuación, se introduce mediante un conector adversativo la ilocución la principal de tipo ASERTIVo (1.): se trata de un acto de habla indirecto cuyo valor performativo es CRITICAR: Sin embargo, me resulta difícil encontrar otro motivo de elogio, que expresa el propósito fundamental del productor. A partir de allí se suceden ilocuciones de apoyo de tipo subsidiario, destinadas a fundamentar la ilocución principal; se trata de cuatro aserciones y una ilocución final expresiva, todas con valor performativo de CRITICAR:

1.1. EXPRESIVA / COMPLEMENTARIA. La publicación (...) me parece un acto de estricta justicia

1. ASERTIVA / PRINCIPAL. Sin embargo, me resulta difícil encontrar otro motivo de elogio

1.2. ASERTIVA/SUBORDINADA la totalidad de los artículos tiene un carácter histórico

1.3. ASERTIVA/ SUBORDINADA este particular enfoque hace que la lectura se haga pesada

1.4. ASERTIVA/ SUBORDINADA Comparto... pero esta necesidad podría haberse reflejado en dos o tres crónicas o entrevistas

1.5. ASERTIVA / SUBORDINADA La acumulación de notas históricas parece más propia de un obituario que de...

1.6. EXPRESIVA/ SUBORDINADA Lamenté, fundamentalmente, la ausencia de notas de divulgación...

El autor de la carta realiza un ataque directo, sin mitigación, a la imagen pública de los editores: ese ataque frontal (en 1.) se despliega en la serie de aserciones cuyo contenido proposicional incluye valoraciones negativas. En 1.5., encontramos una ilocución asertiva que incluye una valoración negativa, con alto grado de agresividad (La acumulación de notas históricas parece más propia de un obituario...) que se complementa con una ilocución final de tipo expresivo, con un performativo explícito - 'lamenté'- que refuerza la evaluación completamente negativa del volumen. Como puede verse, el autor de este texto no atiende en absoluto el principio de cortesía, sino que lesiona de manera directa y sin mitigación de ningún tipo la imagen de los editores. 
La jerarquía ilocutiva se presenta a continuación en un diagrama arbóreo; se grafica el carácter simple de esta jerarquía, compuesta de una ilocución principal, una ilocución de apoyo complementaria ('aseguradora de la cooperación') y varias ilocuciones subsidiarias que fundamentan la principal:

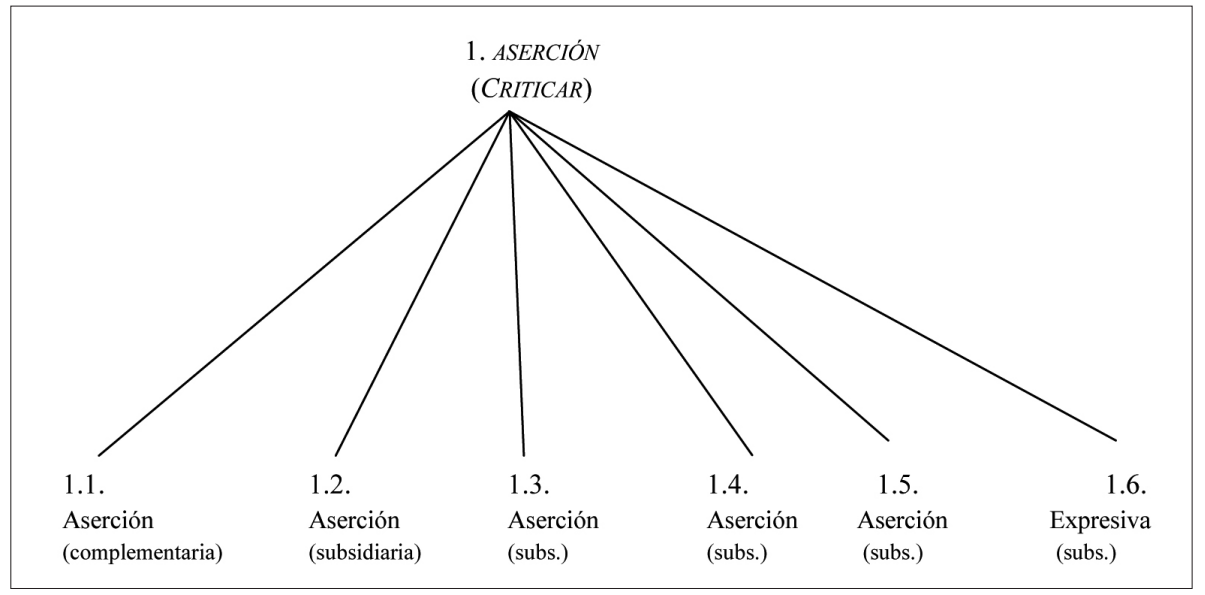

Figura 2. Jerarquía ilocucionaria del texto CL0006a.

A continuación, se presenta el análisis de la respuesta de los editores (ver Apéndice A, Jubileo del Instituto Balseiro - CL0006b).

Como puede observarse en la respuesta, los editores reaccionan a la carta del lector con un texto que desde el punto de vista funcional significa una RÉpLICA, pero que se formula bajo la forma de ASERCIONES, en gran medida despojadas de expresiones subjetivas o formas que lesionen de manera directa la imagen del lector. Concretamente la secuencia de actos de habla está conformada por una ilocución dominante de tipo ASERTIVo, que incluye otras ilocuciones subsidiarias ASERTIVAS, las cuales contienen la información que fundamenta la posición de los editores (fundamentación semántica que se explicita con el subordinante 'porque') y descalifican de modo relativamente elegante la crítica del lector:

1. ASERCIÓN (RÉPLICA)/PRINCIPAL. Los editores optaron por dar a todo el número un enfoque histórico, entre otras razones, porque...

1.1. ASERCIÓN/SUBORDINADA. La complejidad de la cuestión excede por mucho la posibilidad de despacharla "en dos o tres crónicas o entrevistas" 
1.2. ASERCIÓN/SUBORDINADA. Los artículos que reclama el lector se publican regularmente en Ciencia Hoy

1.3. ASERCIÓN/SUBORDINADA. La siguiente lista indica a diez de ellos:...

La devolución de la agresividad recibida se realiza de manera contenida en dos estrategias principales, que consisten en la elección de recursos lingüísticos de distinto orden. En primer lugar, en la ASERCIÓN 1.1. se desautoriza al lector destacando la complejidad de la cuestión y adscribiéndole un grado de desconocimiento de la misma. El empleo del verbo 'despachar' (RAE. Despachar: (del ant. Fr. despeechier.) tr. Abreviar y concluir un negocio u otra cosa. (...) y la cita directa de las palabras del autor de la carta lesionan su imagen, al colocarlo en posición de ignorancia y superficialidad. En segundo lugar, como remate de la réplica contenida, las aserciones 1.2. y, especialmente, la 1.3., con una función especificadora, que detalla a 1.2. bajo la forma de una pormenorizada lista de referencias bibliográficas retrucan con contundencia el reclamo del lector, al que se lo atiborra de informaciones que nuevamente lo colocan en el lugar de desconocimiento (una posición por demás incómoda en una revista de comunicación científica). La descortesía de la carta original es sancionada por los editores con aspereza, aspereza que se logra con una estrategia que reprime la expresión de valoraciones negativas pero que tiene un alto grado de efectividad discursiva.

La jerarquía ilocutiva que se construye en este texto es simple: la ilocución principal ASERTIVA (1.1.) se fundamenta en tres ilocuciones de apoyo, también asertivas; a continuación el diagrama arbóreo:

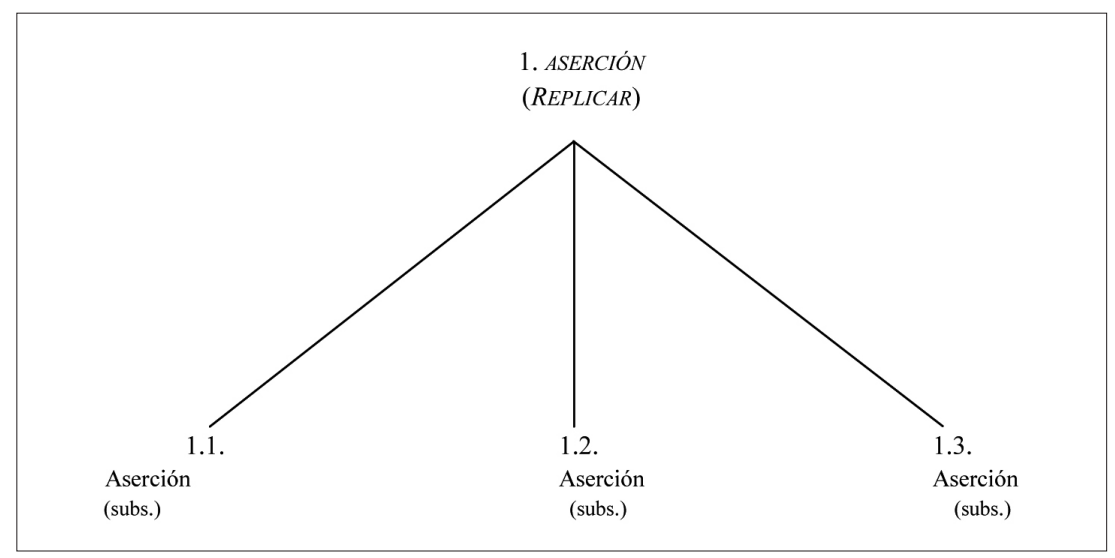

Figura 3. Jerarquía ilocucionaria del texto CL0006b. 


\subsubsection{Caso 2: Acuerdo y cortesía}

El intercambio que se presenta como Caso 2 (ver Apéndice A) es más complejo desde el punto de vista de la estructura ilocucionaria, puesto que pueden identificarse más de una jerarquía ilocucionaria y porque el trabajo interaccional es más elaborado; por otra parte, este intercambio da como resultado el acuerdo en las posiciones, a diferencia del caso anterior. En el corpus en general puede observarse la tendencia a expresar de manera explícita la fuerza ilocutiva de los enunciados, mayormente, mediante verbos performativos u otras clases de palabras que conservan ese significado accional, especialmente, nominalizaciones. Es el caso de la carta 'Cuestiones de nomenclatura' (CL0001a), que se inicia con una ilocución complementaria dirigida a la relación con el interlocutor: "En primer lugar, una felicitación por el editorial del número 84 'Una mutación del Homo academicus'”. Como lo muestran los ejemplos seleccionados, es muy usual en las cartas de Ciencia Hoy el inicio mediante una ilocución complementaria -generalmente FELICITAR O VALORAR POSITIVAMENTE- orientada a sustentar la ilocución principal, morigerando los efectos negativos de la crítica.

A continuación, una presentación más detallada de la secuencia de ilocuciones, con sus formulaciones lingüísticas:

1.1. / 2.1. EXPRESIVA / COMPLEMENTARIA: En primer lugar, una felicitación por el editorial del número 84 "Una mutación del Homo academicus"

1.1.1. ASERCIÓN/SUBSIDIARIA: El personaje que describe es abundante (...)

1.1.2. ASERCIÓN/SUBSIDIARIA: La descripción que hace el editorialista ayudará a ...

1. ASERCIÓN. (CRITICAR)/PRINCIPAL: Dicho esto, permítanme notar, a propósito de los buenos artículos sobre nanotecnología publicados en el mismo número que no siempre se respetaron las convenciones internacionales en cuanto a símbolos y terminología.

1.2. ASERCIÓN/ SUBSIDIARIA. Así, se usó micrón en vez de micrómetro (...)

1.3. ASERCIÓN/ SUBSIDIARIA. En otro lugar se simbolizó la energía de Fermi con $\mu$, escrito en tipografía redonda, cuando debió ponerse en cursiva por ser una magnitud (...)

1.4. ASERCIÓN/ SUBSIDIARIA. Además el símbolo acordado es ...

1.5. ASERCIÓN/ SUBSIDIARIA. En otra nota se usó Torr (...)

2. DIRECTIVO-SUGERIR/PRINCIPAL: Sugiero que el respeto por la simbología internacional sea una política editorial, como se viene recomendando desde hace ya bastante tiempo

El acto amenazante de CRITICAR -la ilocución principal- se presenta entonces de manera estratégica con una ilocución complementaria expresiva ('felicitar'): luego del trabajo de cortesía positiva), el lector con una especie de hiato discursivo ('dicho esto') que anuncia el cambio de orientación enunciativa, introduce la crítica mediante una fórmula de cortesía con el verbo modal 'permitir' y una valoración positiva de los artículos ('buenos artículos'); el 'pedido de 
permiso' crea la ficción interpretativa de haber sido, con ese acto, 'autorizado' a criticar. Las ilocuciones que realizan OBJECIONES (1.2., 1.3., 1.4. etc.) son aserciones formuladas de manera impersonal; en términos de Caffi (1999), se emplean 'escudos' (shields) para proteger la imagen pública de los editores: así emplea pasivas con se (1., 1.2., 1.3, 1.5.). La ilocución directiva de cierre (2. SUGERIR) se acompaña de una recriminación embozada ('como se viene recomendando desde hace ya bastante tiempo'), que representa una amenaza para la imagen de los interlocutores, si bien mitigada nuevamente por una formulación impersonal.

A continuación la estructura jerárquica compleja, que comprende dos ilocuciones principales interrelacionadas (CRITICAR-SUGERIR), sustentadas conjuntamente por la ilocución complementaria expresiva (1.1., 2.1.); la ilocución 1. (CRITICAR), a su vez, es apoyada por las ilocuciones subsidiarias (1.2. a 1.5.).

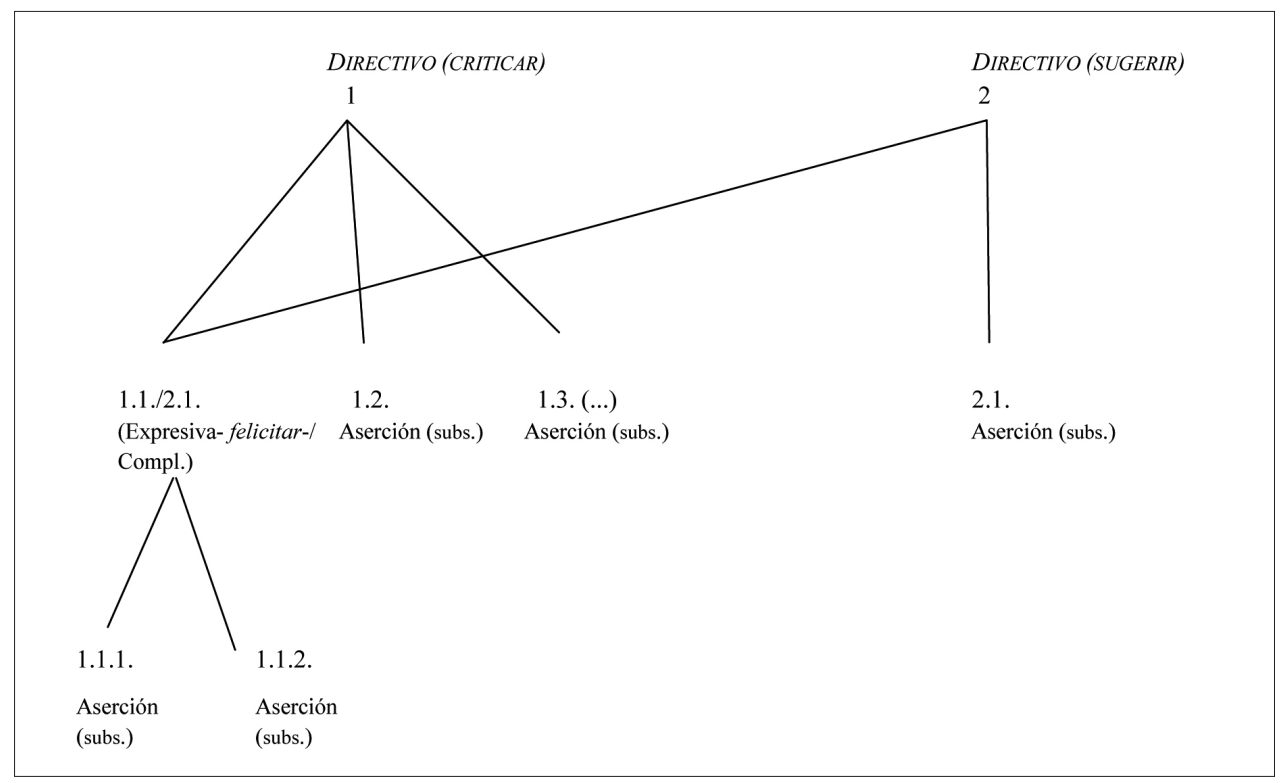

Figura 4. Jerarquía ilocucionaria del texto CL0001a.

Veamos ahora la respuesta que merece la carta CL0001a sobre nomenclaturas por parte de los editores: si se lee con atención CL0001b, se constata que los editores han adoptado una estrategia similar, casi en espejo a la del lector. Debido a la extensión de esta carta, se presenta a 
continuación una descripción lineal de las ilocuciones principales y subordinadas más importantes y se omiten algunas subordinadas menos relevantes:

1.1. EXPRESIVA/COMPLEMENTARIA: Se agradece al lector su comentario sobre el editorial

1.2. EXPRESIVA/COMPLEMENTARIA: Sus observaciones sobre nomenclatura y simbología son muy oportunas y apuntan en la dirección en la que CIENCIA HOY procura avanzar (...) 1. ASERCIÓN (REFUTAR)/PRINCIPAL: Hay, sin embargo, que tener en cuenta que los usos y costumbres muchas veces no se amoldan (o tardan en amoldarse) a las convenciones internacionales.

1.3. ASERCIÓN (REFUTAR)/SUBSIDIARIA: En ese sentido, el empleo del término micrón, como simplificación del vocablo micrómetro (no como unidad que lo sustituye), puede entrar en la categoría de lo aceptado (...)

2. ASERCIÓN (ADMITIR): Mm fue, como la del título del editorial, otra errata (la letra griega $\mu$ salió como $M$, algo que no se advirtió en la corrección).

2.1. ASERCIÓN (ADMITIR): También la $\mu$ de la energía de Fermi debió aparecer en itálica (...) 1.4. ASERCIÓN (REFUTAR)/SUBSIDIARIA): Pero el uso de milibares (milésimas de bar) es común en Europa, y el de Torr en los EEUU y Asia.

1.5. ASERCIÓN (REFUTAR) /SUBSIDIARIA): La presión de vacío se expresa generalmente en Torr, unidad que no parece haber caído tan en desuso (...)

3. ASERCIÓN (ACORDAR): Los editores coinciden con la recomendación del lector Bertello de incorporar a las políticas editoriales el respeto por la nomenclatura y la simbología internacionales.

3.1. ASERCIÓN/SUBSIDIARIA. Erratas aparte, así lo han tratado de hacer (...)

4. COMPROMISIVO/PRINCIPAL. En lo sucesivo, Ciencia Hoy procurará señalar esos desvíos de los usos y costumbres con relación a las convenciones internacionales y, cuando sea del caso, dar ambas unidades.

Como puede verse en la descripción, el primer fragmento -que abarca las dos primeras oraciones- se dedica al 'agradecer' y al saludar positivamente las observaciones formuladas ('sus observaciones... son muy oportunas'); además, se explicita la coincidencia de la revista con la posición general del lector. Acto seguido, se presenta el movimiento contrario en la primera ilocución principal, esto es, el distanciamiento o la réplica, marcada por un conector adversativo que inicia una secuencia argumentativa (1.): 'hay sin embargo, que tener en cuenta que los usos y costumbres muchas veces no se amoldan (o tardan en amoldarse) a las convenciones internacionales, aun entre científicos y tecnólogos...)'. A partir de allí, se sigue un movimiento alternante de ilocuciones de REFUTACIÓN (1.3.) y ADMISIÓN (2., 2.1. y ss.) de erratas. Las 'admisiones' se realizan generalmente bajo la forma de aserciones con polaridad positiva ('Mm fue, como la del título del editorial, otra errata'); las 'réplicas' se realizan bajo la forma de estructuras argumentativas, en las que son frecuentes las negaciones y los coordinantes 
adversativos. En 1.4. la 'réplica' se encabeza con el conector adversativo 'pero'; 1.5., que continúa la réplica, incluye una secuencia argumentativa con negación ('que no parece haber caído tan en desuso'). La última ilocución, que realiza el cierre de la carta, es la enunciación explícita de un 'compromiso' de los editores respecto del comportamiento futuro respecto de las convenciones terminológicas (4.).

Este texto exhibe una estructura jerárquica más compleja que los anteriores, en la que se verifican cuatro ilocuciones principales: 1. REFUTAR, 2. ADMITIR, 3. ACORDAR, 4. COMPROMETERSE; las dos primeras, a su vez, son apoyadas por varias ilocuciones subordinadas. La ilocución principal 1. es además sostenida por las ilocuciones complementarias (1.1. y 1.2.) que indirectamente colaboran con el vínculo con los interlocutores y así con la aceptación de los argumentos incluidos en los movimientos de refutación y admisión. El esquema jerárquico de las ilocuciones (simplificado) se ofrece a continuación:

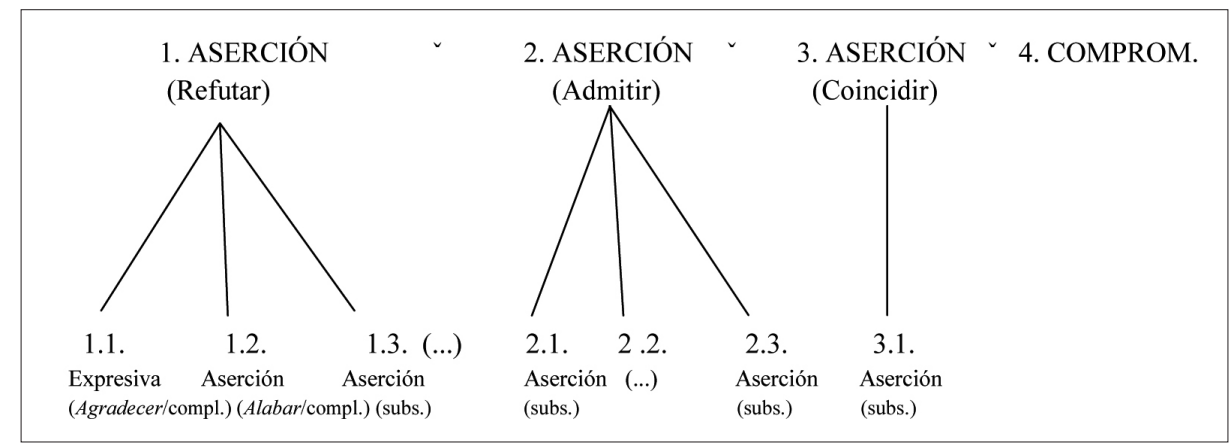

Figura 5. Jerarquía ilocucionaria del texto CL0001b.

En cuanto a las estrategias de mitigación que aparecen en las admisiones se destacan nuevamente los escudos para proteger la imagen de los editores: la formulaciones impersonales (por ej. en 2. 'Mm fue, como la del título del editorial otra errata; algo que no se advirtió'; en 2.1. 'debió aparecer en itálica', etc.). Las referencias directas a los productores del texto aparecen solamente en las ilocuciones no amenazantes, que significan cortesía positiva: por ejemplo en la ilocución principal 3. que manifiesta el acuerdo ('Los editores coinciden...') y en la ilocución final de compromiso, con el nombre de la revista (Ciencia Hoy).

Si se observa la disposición lineal de las ilocuciones en este intercambio puede formularse una generalización, coincidente con los resultados de Brandt y Rosengren (1992) para las cartas 
comerciales: los distintos tipos de ilocuciones tienden a disponerse en una progresión que tiene cierta sistematicidad. A saber, las ilocuciones de apoyo complementarias son las más externas (inicio o cierre del texto), las ilocuciones de apoyo subsidiarias vienen a continuación y, finalmente, las ilocuciones principales suelen ocupar un lugar central en el texto:

$<$ iloc. de apoyo cooperativas $><i l o c$. de apoyo subsidiarias $><i l o c$. principales $><i l o c . ~ a p o y o$ subsidiarias> (< iloc. apoyo cooperativas>)

En síntesis: la carta del lector y la respuesta de los editores muestran un esquema ilocutivo complementario, que alcanza un resultado final positivo para la interacción, en el que se ha logrado un acuerdo general sobre el tema de discusión, aunque se han defendido las divergencias, y los interlocutores -lector y editores- han llevado a cabo un trabajo de imagen positiva que colabora con el acuerdo sobre las normas respecto de las nomenclaturas.

\section{CONCLUSIONES}

El examen de los casos 1 y 2, que se han elegido en esta presentación como ejemplos paradigmáticos de los intercambios polémicos que sostienen lectores, editores y autores de la revista Ciencia Hoy, permite arribar a algunas conclusiones respecto de la estructura accional (nivel funcional) del género, de las formas y recursos elegidos para su realización lingüística, así como sobre el trabajo de cortesía que emplean los interlocutores en la discusión y elaboración de conocimiento especializado.

En cuanto al conjunto de las cartas de lectores de Ciencia Hoy estudiado, puede concluirse que desde el punto de vista funcional se pueden distinguir tres subconjuntos, que se han diferenciado según el tipo de ilocución(es) principal(es). Las cartas tipo C -foco de este análisis- constituyen desde el punto de vista ilocutivo un directivo complejo: en este primer trabajo se ha concentrado la atención en los intercambios diádicos, los cuales se realizan mediante jerarquías ilocutivas simples y complejas, que dan como resultado el 'Acuerdo' o el 'Desacuerdo' sobre el tema de la polémica y variadas constelaciones $(+/$ - corteses) en las relaciones interpersonales (ver Tabla 3). 
Tabla 3. Estructura ilocutiva y su realización lingüística en las cartas de lectores tipo C.

\begin{tabular}{|l|l|}
\hline $\begin{array}{l}\text { Nivel 1: } \\
\text { Funcionalidad }\end{array}$ & $\begin{array}{l}\text { (Macro) Funciones principales } \\
\text { Cartas tipo C: DIRIGIR (refutar o criticar o sugerir o admitir) e } \\
\text { informar y/o comprometerse }\end{array}$ \\
\hline $\begin{array}{l}\text { Nivel 4: } \\
\text { Forma lingüística }\end{array}$ & $\begin{array}{l}\text { Cartas tipo C: Estilo directo para la realización de actos directivos; } \\
\text { predicaciones con realizativos explícitos (verbos y construcciones } \\
\text { equivalentes como, por ejemplo, nominalizaciones). Esquemas } \\
\text { oracionales declarativos para aserciones con valor accional de } \\
\text { refutación y réplica. }\end{array}$ \\
$\begin{array}{l}\text { Formas expresivas directas del trabajo de cortesía (felicitaciones, } \\
\text { agradecimientos, etc.). Empleo de escudos para las referencias al } \\
\text { interlocutor, tendencia a la desagentivación para la formulación } \\
\text { de críticas y réplicas, mediante construcciones pasivas con se y } \\
\text { oraciones impersonales. }\end{array}$ \\
\hline
\end{tabular}

El análisis realizado ha podido poner de manifiesto que las acciones textuales complejas se realizan sobre la base de unidades accionales menores, las ilocuciones subordinadas de tipo complementario o subsidiario, que van tejiendo una configuración accional, sostenida y anclada en la estructura informativa. En este sentido, la investigación abona la tesis formulada en trabajos teórico-descriptivos como los de Brandt y Rosengren (1992) y Schröder (2003), que proponen una estructura de constituyentes para el nivel accional del texto.

En el corpus estudiado se observa la tendencia por la realización explícita de los actos de habla, tanto los EXPREsivos (que colaboran con la aceptación de las críticas y réplicas) como los actos de REFUTACIÓN Y RÉPLICA que amenazan la imagen del otro: mediante verbos o expresiones performativas explícitas los autores de los textos discuten y debaten sobre los temas específicos y toman posición clara sobre los mismos. Hemos relevado esquemas oracionales declarativos para la realización de aserciones con fuerza performativa de REFUTACIÓN O ADMISIÓN. En cuanto al trabajo de cortesía, en cada caso particular, se realiza con mayor o menor esmero, pero, en general, se observa la tendencia al empleo de los recursos propios de la protección de la imagen del otro, especialmente mediante 'escudos' en las ilocuciones amenazantes de la imagen y la inclusión de actos corteses en los tramos iniciales de los textos, que morigeran las críticas y réplicas directas que caracterizan a este subconjunto de cartas de lectores de ciencia. El desacuerdo frontal (que se ha ilustrado en el caso 1) generalmente se realiza mediante el rechazo plano de los argumentos del otro, y su ubicación discursiva en el lugar del desconocimiento, sanción 
máxima en el ámbito social en que funcionan estos textos, y se acompaña de un estilo despojado en cuanto a los recursos de cortesía.

La investigación presentada ofrece conocimientos empíricos sobre la estructura retórico-ilocutiva de las cartas de ciencia, y sobre los recursos de cortesía o descortesía que emplean los lectores y autores especialistas cuando discuten sobre temas de su especialidad. En términos generales, puede decirse que predomina en el corpus un estilo frontal para la discusión de argumentos, que se mitiga con recursos de cortesía, según el caso particular. Los resultados descriptivos alcanzados sobre el género y su estructura ilocutiva e interaccional podrían emplearse como insumos para proponer y desarrollar lineamientos, estrategias y recursos didácticos para la capacitación en la producción y comprensión de textos científicos.

\section{REFERENCIAS BIBLIOGRÁFICAS}

Adamzik, K. (2004). Textlinguistik. Eine Einführung. Tübingen: Niemeyer.

Álvarez, M. (1995). Tipos de escrito III: Epistolar, administrativo y jurídico. Cuadernos de la lengua española. Madrid: Arco Libros.

Bergmann, J. \& Luckmann, T. (1995). Reconstructive genres. En U. Quasthoff (Ed.), Aspects of Oral Communication (pp. 289-304). Berlin: W. de Gruyter.

Bernárdez, E. (1995). Teoría y epistemología del texto. Madrid: Cátedra.

Brandt, M. \& Rosengren, I. (1992). Zur Illokutionsstruktur von Texten. Lili, 86, 9-51.

Brinker, K. (1988 [2001]). Linguistische Textanalyse. Berlin: E. Schmidt.

Brown, P. \& Levinson, S. (1987). Politeness, some universals in language usage. Cambridge: Cambridge University Press.

Caffi, C. (1999). On mitigation, Journal of Pragmatics, 31(7), 881-909.

Ciapuscio, G. (2007). Genres et familles de genres: Apports pour l'acquisition de la competence generique dans le domaine academique. Études de Linguistique Apliquée, 4(148), 405416.

Ciapuscio, G., Adelstein, A. \& Gallardo, S. (2010). El texto especializado: Propuesta teórica y prácticas de capacitación académica y profesional en la Argentina. En G. Parodi (Ed.), Alfabetización académica y profesional en el Siglo XXI: Leer y escribir desde las disciplinas (pp. 317-346). Santiago: Editorial Planeta. 
Gallardo, S. (2005). Propósito instructivo y formulaciones corteses. La recomendación en las notas periodísticas sobre salud. En D. Bravo (Ed.), Estudios de la (des)cortesía en español (pp. 188-219). Estocolmo/Buenos Aires: Dunken.

Heinemann, W. (2000). Textsorten. Zur Discusión um Basisklassen des Kommunizierens. Rückschau und Ausblick. En K. Adamzik (Ed.), Textsorten (pp. 9-29). Tübingen: Stauffenburg Verlag Brigitte Narr GmbH.

Heinemann, W. \& Viehweger, D. (1991). Textlinguistik. Eine Einführung. Tübingen: Niemeyer.

Heinemann, M. \& Heinemann, W. (2002). Grundlagen der Textlinguistik. Tübingen: Max Niemeyer Verlag.

Leech, G. (1983). Principles of pragmatics. London: Longman.

Schröder, H. (2003). Die Handlungscharakter von Texten. Tübingen: Gunter Narr.

\section{NOTAS}

1 En un trabajo reciente (Ciapuscio, Adelstein \& Gallardo, 2010), sobre la base de una modelización radial de las dimensiones presentada por Adamzik (2004), hemos propuesto una reformulación de la misma que creemos más satisfactoria, puesto que permite resolver inadecuaciones teóricas y empíricas en el análisis lingüístico de textos, y permite representar cómo interactúan y se condicionan de manera recíproca las informaciones de las distintas dimensiones.

2 Álvarez (1995).

3 Gallardo (2005) ha estudiado también la cortesía en textos de divulgación de la medicina a través de la prensa, centrándose en la gestión de la cortesía cuando se formulan consejos.

4 En entrevistas entre médicos y pacientes analiza distintos recursos expresivos de estas categorías: para los bushes, son típicos los diminutivos; los hedges están representados por los modos verbales -en español típicamente el condicional- y los 'escudos' abarcan los diferentes recursos que logran sacar de foco a la fuente o responsable de la ilocución.

5 http://www.cienciahoy.org.ar/hoy110/index.htm

6 http://www.caicyt.gov.ar/coteca

7 En su editorial fundacional del año 1988 se explicita que la revista "Pretende acceder a un espectro de lectores mucho más amplio, que abarque desde el ciudadano interesado individualmente en la ciencia hasta el planificador, el empresario y el gobernante, sin olvidar al docente y al estudiante".

8 La tipificación se orienta también en la categorización de Brandt y Rosengren (1992) quienes distinguen cuatro tipos básicos, reformulando parcialmente la clásica propuesta de Searle: a) representativos (aserción y pregunta); b) expresivos y c) regulativos; dentro de estos incluyen los directivos y los comisivos. Los distintos tipos responden a fórmulas específicas, en las que el criterio distintivo es el tipo de predicado ilocucionario. Las subcategorías que postulo en este trabajo para describir los actos de habla particulares (por ejemplo, 'criticar') se escogen toman- 
do como criterio las definiciones lexicográficas de los verbos en correspondencia con el contenido del texto.

9 Reproduzco la primera carta para que el lector del artículo se familiarice con el género; el conjunto de las cartas con que se ilustran los resultados se incluyen en el apéndice A. En los textos se numeran las ilocuciones más importantes, que luego se citan en los esquemas secuenciales y jerárquicos.

10 Aunque cabe pensar que han sido editadas y reformuladas por el comité editorial.

11 La carta más breve del corpus tiene 32 palabras; la más extensa, 3714.

12 Con mayúsculas señalamos las ilocuciones dominantes o principales.

\section{APÉNDICE A}

\section{Caso 1:}

\section{Carta iniciadora}

\section{Jubileo del Instituto Balseiro (CL0006a)}

1.1. La publicación del número 88 de la revista, dedicado en su totalidad al aniversario del Instituto Balseiro, me parece un acto de estricta justicia, dada la necesidad de revalorizar en la Argentina el esfuerzo, el estudio y la investigación científica. 1. Sin embargo, me resulta difícil encontrar otro motivo de elogio. 1.2. La totalidad de los artículos tiene un carácter histórico, de conmemoración de sucesos pasados. 1.3. Este particular enfoque hace que la lectura se haga pesada, porque los mismos nombres, hechos y circunstancias se repiten una y otra vez a lo largo de 60 páginas. 1.4. Comparto con el editor que "Comprender la historicidad y los componentes socioculturales de la producción científica y tecnológica resulta necesario", pero esta necesidad podría haberse reflejado en dos o tres crónicas o entrevistas (en cualquier caso, la investigación histórica del Balseiro no se agotó con este número de Ciencia Hoy). 1.5. La acumulación de notas históricas parece más propia de un obituario que del 50 aniversario de una institución en crecimiento. 1.6. Lamenté, fundamentalmente, la ausencia de notas de divulgación realizadas por investigadores actuales del instituto sobre las investigaciones en curso o proyectadas.

\section{Gerardo Rodríguez Planes}

Médico cirujano en los hospitales Churruca y Durand

\section{Respuesta}

Jubileo del Instituto Balseiro (CL0006b)

1. Los editores optaron por dar a todo el número un enfoque histórico, entre otras razones, porque 1.1. la complejidad de la cuestión excede por mucho la posibilidad de despacharla "en dos o tres crónicas o entrevistas", y 1.2. porque los artículos que reclama el lector se publican regularmente en Ciencia Hoy. 1.3. La siguiente lista indica a diez de ellos: (1) 
Alejandro Butera, “Grabación magnética”, 86:24-31, (2) Guillermo Zampieri et al., “Dónde están los átomos?", 86:34-39, (3), Rodolfo Sánchez y Roberto Zysler, "Magnetismo de sistemas nanoscópicos, algunas aplicaciones", 85:40-51, (4) Alejandro Fainstein y Karen Hallberg, "La física de alambres moleculares, átomos artificiales y cavidades nanoscópicas", 84:16-23, (5) Carlos Balseiro y Gonzalo Usaj, "Transportando electrones en circuitos de escala molecular", 84:24-32, (6) Julio Guimpel y Hernán Pastoriza, “Arquitectura a escala nanoscópica”, 84:34-39, (7) Karen Hallberg, "Nanomemoria”, 73:24-25, (8) Ingomar Allekotte y Diego Harari, "Un desafío cósmico para el Observatorio Auger", 71:49-60, (9) Ernesto Martínez y Rodolfo Pregliasco, "El sonido de una hoja. Estudio acústico de un homicidio", 63:12-23, (10) Verónica Grünfeld, “Física médica y bioenergía”, 33:59-64.

\section{Caso 2:}

\section{Carta iniciadora}

\section{Cuestiones de nomenclatura (CL0001a)}

1.1. / 2.1.En primer lugar, una felicitación por el editorial del número 84 "Una mutación del Homo academicus". 1.1.1. El personaje que describe es abundante y, lamentablemente, resulta promovido por los medios y hasta premiado por sociedades extranjeras. 1.1.2. La descripción que hace el editorialista ayudará a desenmascarar estos especímenes. 1. Dicho esto, permítanme notar, a propósito de los buenos artículos sobre nanotecnología publicados en el mismo número que no siempre se respetaron las convenciones internacionales en cuanto a símbolos y terminología. 1.2. Así, se usó micrón en vez de micrómetro y, como símbolo de esa unidad, $M n$ (que significa megametro) en lugar de $\mu \mathrm{m}$. 1.3. En otro lugar se simbolizó la energía de Fermi con $\mu$, escrito en tipografía redonda, cuando debió ponerse en cursiva por ser una magnitud: además el símbolo acordado es Er. 1.4. Se mezclaron magnitudes con unidades al escribir que la corriente I (debió ser $I$ ) no es proporcional al voltaje $V$ (debió decir al potencial eléctrico, símbolo $V$, ya que $V$ en tipo redondo es el símbolo de volt). 1.5. En otra nota se usó Torr (símbolo del torricelli) como unidad de presión, caída en desuso hace más de 30 años, en lugar del pascal (símbolo Pa). 2. Sugiero que el respeto por la simbología internacional sea una política editorial, como se viene recomendando desde hace ya bastante tiempo.

Luis F. Bertello

Chemiconsult, San Isidro

\section{Respuesta}

\section{Cuestiones de nomenclatura (CL0001b)}

1.1. Se agradece al lector su comentario sobre el editorial (en cuyo título, Homo academicus debió haber aparecido en itálica, como estaba en el original que fue a composición, pero...). 1.2. Sus observaciones sobre nomenclatura y simbología son muy oportunas y apuntan en la dirección en la que Ciencia Hoy procura avanzar para hacer un uso aceptado e inequívoco de la terminología sobre magnitudes y unidades. 1. Hay, sin embargo, que tener en cuenta que los 
usos y costumbres muchas veces no se amoldan (o tardan en amoldarse) a las convenciones internacionales, aun entre científicos y tecnólogos. 1.3. En ese sentido, el empleo del término micrón, como simplificación del vocablo micrómetro (no como unidad que lo sustituye), puede entrar en la categoría de lo aceptado, no así su sinónimo micra, el cual se fue eclipsando pero, como aquel, figura en el diccionario de la Real Academia Española, que define a ambos como la millonésima parte de un metro. 1.3.1. Este, como se sabe, es la unidad de longitud, una de las siete fundamentales (las otras son el kilogramo, el segundo, el amperio, la candela, el mol y el kelvin) del sistema internacional de medidas (cuya sigla es SI en cualquier idioma), aprobado en 1960 por la XI conferencia internacional de pesas y medidas y, consecuentemente, base del sistema métrico legal argentino. 2. Mm fue, como la del título del editorial, otra errata (la letra griega $\mu$ salió como $M$, algo que no se advirtió en la corrección). 2.1. También la $\mu$ de la energía de Fermi debió aparecer en itálica y, si bien es más frecuente indicarla con la notación $E F$, la $\mu$ es preferida por muchos autores. 2.2. Lo mismo sucedió con la corriente eléctrica, que debió expresarse como I (cursiva), y con la diferencia de potencial, que debió ir como $V$ (cursiva). 2.2.1. El término voltaje es un anglicismo aceptado (voltage) para expresar la diferencia de potencial. 2.2.2. El Pascal es, por cierto, la unidad del sistema internacional para medir presión. 1.4. Pero el uso de milibares (milésimas de bar) es común en Europa, y el de Torr en los EEUU y Asia. 1.5. La presión de vacío se expresa generalmente en Torr, unidad que no parece haber caído tan en desuso. 3. Los editores coinciden con la recomendación del lector Bertello de incorporar a las políticas editoriales el respeto por la nomenclatura y la simbología internacionales. 3.1. Erratas aparte, así lo han tratado de hacer. 3.2. Al mismo tiempo, han querido en muchos casos respetar las unidades utilizadas por los autores, en especial en aquellos casos en que reflejan los usos y costumbres de alguna rama disciplinaria o profesión. 3.2.1. En los medios técnicos locales del automóvil, para poner un ejemplo elocuente, resultaría incomprensible especificar que en verano se inflen las gomas hasta $200 \mathrm{kPa}$, en vez de hasta las consabidas 29 libras (o, más técnicamente, PSI, del inglés pounds per square inch, libras por pulgada cuadrada). 3.2.2. En Europa hablarán de kg por cm cuadrado. 4. En lo sucesivo, Ciencia Hoy procurará señalar esos desvíos de los usos y costumbres con relación a las convenciones internacionales y, cuando sea del caso, dar ambas unidades. 